\title{
Correction to: Optimal Controlled Transports with Free End Times Subject to Import/Export Tariffs
}

\author{
Samer Dweik ${ }^{1} \cdot$ Nassif Ghoussoub $^{1} \cdot$ Aaron Zeff Palmer ${ }^{1}$ \\ Published online: 07 April 2021 \\ (C) Springer Science+Business Media, LLC, part of Springer Nature 2021
}

Correction to: Journal of Dynamical and Control Systems (2020) 26:481-507. https://doi.org/10.1007/s10883-019-09458-1

In the published article "Optimal Controlled Transports with Free End Times Subject to Import/Export Tariffs", incorrect pagination is spotted. In the PDF of this article, pages 482-507 were incorrectly numbered.

The original article has been corrected.

Publisher's Note Springer Nature remains neutral with regard to jurisdictional claims in published maps and institutional affiliations.

The online version of the original article can be found at https://doi.org/10.1007/s10883-019-09458-1

Samer Dweik

dweik@math.ubc.ca

1 Department of Mathematics, University of British Columbia, Vancouver, BC V6T 1Z2, Canada 